\title{
Fractal Dimension of Active-Site Models of Zeolite Catalysts
}

\author{
Francisco Torrens $^{1}$ and Gloria Castellano ${ }^{2,3}$ \\ ${ }^{1}$ Institut Universitari de Ciència Molecular, Universitat de València, Edifici d'Instituts de Paterna, \\ P.O. Box 22085, 46071 València, Spain \\ ${ }^{2}$ Departamento de Química, Universidad Politécnica de Valencia, Camino de Vera s/n, \\ 46022 València, Spain \\ ${ }^{3}$ Departamento de Ciencias Experimentales, Facultad de Ciencias Experimentales, \\ Universidad Católica de Valencia San Vicente Mártir, Guillem de Castro 94, 46003 València, Spain
}

Received 20 March 2006; Revised 31 May 2006; Accepted 9 June 2006

A method for the calculation of fractal surfaces of crystals is presented. The fractal dimension D of fragments of zeolites is calculated. Results compare well with reference calculations (GEPOL). The active site of Brønsted acid zeolites is modeled by a set of $\mathrm{Al}-\mathrm{OH}-\mathrm{Si}$ units. These units form 2-12-membered rings. Topological indices for the different active-site models are calculated. The comparison between GEPOL and SURMO2 allows calculating the active-site indices. Most cavities show no fractal character, while for the 6-8-unit rings, $D$ lies in the range 4.0-4.3. The 6-ring shows the greatest $D$ and is expected to be the most reactive.

Copyright (c) 2006 F. Torrens and G. Castellano. This is an open access article distributed under the Creative Commons Attribution License, which permits unrestricted use, distribution, and reproduction in any medium, provided the original work is properly cited.

\section{INTRODUCTION}

Zeolites provided an example of the fruitful symbiosis between mineralogists, structural crystallographers, inorganic chemists, and materials scientists. Joint professorships of chemistry and mineralogy were typical in the US during the early 19th century, and mineralogists were listed as one of the six subcategories of chemists in 1870 . Many zeolites were first described as minerals, as well as the chemical substitutions in the frameworks of synthetic zeolites, and the new related microporous aluminophosphate-based materials were known earlier in the feldspar and feldspathoid groups of minerals. The mathematical concepts used to describe the topology of frameworks in zeolites developed from ones known to Greek philosophers, as well as ones used to such stunning effect in Romanesque and Islamic decorations. In the 20th century, development of crystallographic and spectroscopic techniques led to spectacular discoveries about the topochemistry of zeolites. Deliberate control of crystallization processes produced many materials not known in nature. Controlled chemical and physical treatments were used to tailor valuable new products for industry, for example, shape-selective molecular-sieve catalysts. Aluminosilicate zeolites play an increasingly important technological role in the petroleum and petrochemical industries. The properties of zeolites that are exploited in their use as catalysts, sorbents, or ionexchangers reflect particular structural char- acteristics. A detailed knowledge of structure is a prerequisite for understanding zeolite performance. Zeolite structural characterization is hampered by the complexity of zeolite structures, their relatively unfavourable X-ray scattering characteristics, and general unavailability as suitably large single crystals. Problems of phase purity, homogeneity, intergrowths, or stacking disorder are relatively common, preventing the application of traditional methods for structure elucidation; for example, zeolite beta is a near extreme of such stacking disorder.

The catalytic properties of zeolites were determined by the framework composition of the zeolite [1]. Alteration of the $\mathrm{Si} / \mathrm{Al}$ ratio led to dramatic variations in the catalytic activity and stability of the zeolite framework [2]. It was possible to isomorphously substitute certain elements into the framework tetrahedral positions of zeolites [3]. Isomorphously substituted zeolites showed large variations in the polarity and acidity of the framework, and they became also important means by which to tailor zeolites to suit particular catalytic needs. Ab initio molecular-orbital calculations were used to predict structural and acidic properties of zeolites $[4,5]$. By using model-cluster units to represent a portion of the framework surrounding a particular active site, the fundamental difference in acidity between a bridged $\mathrm{Al}$ hydroxyl $(-\mathrm{OH})$ and a free or terminal $-\mathrm{OH}$ was predicted. B [6], Ga, and Ge isomorphously substituted forms were included, with the $\mathrm{B}$ and $\mathrm{Ga}$ forms corresponding to 
isomorphous substitution of $\mathrm{Al}$, as well as the Ge form representing substitution of $\mathrm{Si}$ [7]. The calculated acidic characteristics were in good agreement with experiment. The use of zeolites as acidic catalysts raised interest in the structure and properties of their active sites $[8,9]$. The sources of Brønsted acidity in zeolites are bridged -OHs, which arise from the presence of $\mathrm{Al}$ or $\mathrm{T}^{\mathrm{III}}$ atoms replacing $\mathrm{Si}$ in their structure [10]. The use of nanomaterials with defined structure and properties allows building solid architectures with a precise control at several scales. Zeolites are ideal precursors for building multifunctional hierarchical solids, due to their (1) crystal structure, (2) chemical and thermal stabilities, (3) acidic, interchange, and molecular-sieve properties, (4) low cost, as well as (5) structural and chemical varieties. Some applications are the preparations of (1) advanced zeolites and zeotypes from conventional zeolites via hydrothermal treatment, (2) mesoporous crystal structures of zeolitic walls and their molecular sieve and catalytic properties in the cracking of voluminous hydrocarbons, as well as (3) hierarchical mesoporous silicas from cell-membrane phospholipids and resolutions of these new nanostructures.

In earlier publications, the fractal dimension of different structural-type zeolites was calculated [11]. Correlation models were obtained between the fractal dimension and some topological indices. Some Brønsted-acid models were proposed [12]. The smallest unit $\mathrm{SiH}_{3}-\mathrm{OH}-\mathrm{AlH}_{3}$ represented a bridged $-\mathrm{OH}$, and the remaining models closed rings consisting of $\mathrm{SiH}_{2}-\mathrm{OH}-\mathrm{AlH}_{2}-$ units. An analysis of the geometric and topological indices for the active-site models was performed [13]. The aim of the present report is to perform a comparative study of the properties of a set of Brønsted-acid models representative of $\mathrm{Si}-\mathrm{Al}$ zeolites and to distinguish a particular ring that suggests the greatest reactivity. The smallest investigated unit $\mathrm{SiH}_{3}-\mathrm{OH}-\mathrm{AlH}_{3}$ is taken to represent a bridged $-\mathrm{OH}$. The remaining activesite models are built by closing rings consisting of 2-12 $-\mathrm{SiH}_{2}-\mathrm{OH}-\mathrm{AlH}_{2}-$ units. In the next section, the geometric descriptors and topological indices are described. Following that, the results for the descriptors and indices of different active-site models of zeolites are presented and discussed. The last section summarizes the conclusions.

\section{GEOMETRIC DESCRIPTORS AND TOPOLOGICAL INDICES}

In our program TOPO for the theoretical simulation of the shape of crystal fragments [14], their surface is represented by the external surface of a set of overlapping spheres with appropriate radii, centred on the atomic nuclei [15]. The fragment is treated as a solid in space, defined by tracing spheres around the atomic nuclei. It is computationally enclosed in a graduated rectangular box, and the geometric descriptors evaluated by counting points within the solid or close to chosen surfaces. The fragment volume $V$, surface area $S$, and two topological indices of fragment shape can be calculated. Consider $S_{e}$ as the surface area of a sphere whose volume is equal to the fragment volume $V$ [16]. The ratio $G=S_{e} / S$ is interpreted as a descriptor of fragment globularity. The ratio $G^{\prime}=S / V$ is interpreted as a descriptor of fragment rugosity.

The properties of the systems solvated in water are strongly related to the contact surface between solute and water molecules. Starting from this fact, another molecular geometric descriptor was proposed: the solvent-accessible surface area AS [17]. The AS is defined by means of a probe sphere, which is allowed to roll on the outside while maintaining contact with the bare molecular surface [18]. The AS can be calculated in the same way as the bare molecular surface area by means of pseudoatoms, whose van der Waals radii [19] have been increased by the probe radius $R$ [20]. The accessibility is a dimensionless quantity varying between 0 and 1 , and it also represents the ratio of the solvent-accessible surface area in a particular structure to the solvent-accessible surface area of the same atom when isolated from the molecule. The fractal dimension $D$ of the molecules may be obtained as $D=2-d(\log \mathrm{AS}) / d(\log R)$ [21]. The fractal dimension $D$ provides a quantitative indication of the degree-of-surface accessibility towards different solvents [22]. TOPO allows an atom-to-atom analysis of $D$ on each atom $i$, to obtain an atomic dimension index $D_{i}$ from the atomic contributions to the accessible surface area $\mathrm{AS}_{i}$. The $D_{i}$ can be weight-averaged to obtain a new molecular dimension index $D^{\prime}=\left(\sum_{i} \mathrm{AS}_{i} D_{i}\right) / \mathrm{AS}$, where the $\mathrm{AS}_{i}$ are used as weights for the $D_{i}$. Note that if an $\mathrm{AS}_{i}=0$ for any probe, $D_{i}$ cannot be calculated for atom $i$, and so, this atom does not contribute to $D^{\prime}$. Thus, $D^{\prime}$ represents a $D$ averaged for atoms nonburied (accessible) to any of the solvent-accessible surfaces in the range of probe spheres. In particular, $D^{\prime}=D$ for systems without buried atoms, for example, inert gases, $\mathrm{C}_{60}$, and so forth.

A version of TOPO has been implemented in our versions of programs AMYR [23], GEPOL [24], and SURMO2 [25]. AMYR carries out the theoretical simulation of molecular associations and chemical reactions. GEPOL performs an accurate triangular tessellation of the molecular surface and is used for reference calculations. Both TOPO and GEPOL recognize the cavities in inclusion molecules and are adequate to study intercalation compounds. On the other hand, SURMO2 does not recognize cavities. Furthermore, the combination of SURMO2 and GEPOL results allows the characterization of the molecular surface of internal cavities. Our version of SURMO2 has been corrected for the deviation from the spherical shape, by dividing each point contribution by the cosine of the angle formed by the semiaxis and the corresponding normal vector to the surface at this point. The volume and surfaces of crystal fragments with cavities have been corrected by maximizing, in each angular orientation, the distance of the most distant atom in each semiaxis.

\section{CALCULATION RESULTS AND DISCUSSION}

The following zeolites of different structural types have been studied, namely faujasite, ZSM-11, ZSM-5, mordenite, sodalite, and beta-A. The topological indices calculated for the zeolite crystals are reported (cf. Table 1), including two fragments of faujasite (I and II) with different number of atoms. The faujasite, ZSM-11, ZSM-5, and beta-A structures 
TABLE 1: Topological indices for zeolites.

\begin{tabular}{l|ccccrrr}
\hline Zeolite & $D^{\mathrm{a}}$ & $D^{\prime \mathrm{b}}$ & Framework density $F_{\mathrm{d}}^{\mathrm{c}}$ & Type of rings: $R_{\max }$ & Type of access & $G^{\mathrm{d}}$ & $G^{\prime \mathrm{e}}$ \\
\hline Faujasite-I & 1.866 & 2.317 & 12.7 & 12 & 3 & 0.326 & 0.838 \\
Faujasite-II & 1.912 & 2.193 & 12.7 & 12 & 0.295 & 0.864 \\
ZSM-11 & 1.962 & 2.315 & 17.7 & 10 & 3 & 0.300 \\
ZSM-5 & 2.026 & 2.174 & 17.9 & 10 & 3 & 0.851 \\
Mordenite & 1.961 & 2.058 & 17.2 & 12 & 2 & 0.295 \\
Sodalite & 2.149 & 2.311 & 17.2 & 667 & 0.317 & 0.882 \\
Beta-A & 1.981 & 2.215 & 15.1 & 12 & 3 & 0.225 \\
\hline
\end{tabular}

${ }^{a}$ Fractal dimension of the solvent-accessible surface.

${ }^{b}$ Fractal dimension of the solvent-accessible surface averaged for nonburied atoms.

cThe framework density is expressed as the number of $T$ sites per $1000 \AA^{3}$.

'Fragment globularity.

eFragment rugosity $\left(\AA^{-1}\right)$.

TABLE 2: Geometric descriptors and topological indices for zeolite fragments.

\begin{tabular}{l|rrrrrrrr}
\hline Zeolite & $V^{\mathrm{a}}$ & $S^{\mathrm{b}}$ & $\mathrm{AS}^{\mathrm{c}}$ & $\mathrm{HBAS}^{\mathrm{d}}$ & HLAS $^{\mathrm{e}}$ & $\mathrm{AS}^{\prime \mathrm{f}}$ & $G^{\mathrm{g}}$ & $G^{\text {h }}$ \\
\hline Faujasite-I & 5536 & 4639 & 4163 & 1258 & 2905 & 4742 & 0.326 & 0.838 \\
Faujasite-II & 6844 & 5910 & 5954 & 3986 & 1968 & 6513 & 0.295 & 0.864 \\
ZSM-11 & 6781 & 5773 & 4433 & 2631 & 1802 & 4660 & 0.300 \\
ZSM-5 & 6729 & 5835 & 4789 & 2988 & 1801 & 4752 & 0.295 & 0.851 \\
Mordenite & 5186 & 4576 & 3759 & 2343 & 1416 & 3943 & 0.317 & 0.882 \\
Sodalite & 12157 & 11355 & 7874 & 5429 & 2445 & 6805 & 0.225 \\
Beta-A & 9022 & 7602 & 6295 & 4314 & 1981 & 6389 & 0.276 & 0.934 \\
\hline
\end{tabular}

aFragment volume $\left(\AA^{3}\right)$.

bFragment surface area $\left(\AA^{2}\right)$.

cWater-accessible surface area $\left(\AA^{2}\right)$.

dHydrophobic-accessible surface area $\left(\AA^{2}\right)$.

eHydrophilic-accessible surface area $\left(\AA^{2}\right)$.

fSide-chain-accessible surface area $\left(\AA^{2}\right)$.

gFragment globularity.

h Fragment rugosity $\left(\AA^{-1}\right)$.

show three-dimensional channels, while mordenite shows two-dimensional channels. Each type of zeolite possesses a well-defined crystalline structure, with pores of certain distinct sizes. The studied zeolites cover different pore sizes: faujasite, mordenite, and beta-A are large-pore zeolites (showing channels with access limited by 12-ring windows), while ZSM-11 and ZSM-5 (10-ring) as well as sodalite (6-ring) show smaller windows.

The geometric descriptors and topological indices for the zeolite fragments (cf. Table 2) show a relative error for the fagment volumes $V$ of $0.8 \%$. However, for the fragment surface areas, the errors are larger, for example, $6 \%$ for the bare fragment surface area $S$. Furthermore, the error drops for the water-surface-accessible surface area AS (3\%) and even for the side-chain-accessible surface area $\mathrm{AS}^{\prime}(2 \%)$ due to the internal cavities. The atom-to-atom analysis of the water-accessible surface area AS shows that in general, its hydrophobic term HBAS is almost double than its hydrophilic component part HLAS. In particular, on going from mordenite to sodalite, the geometric descriptors are doubled. On going from sodalite to mordenite, the fragment globularity $G$ increases by $42 \%$. The fragment rugosity $G^{\prime}$ shows the opposite trend. On going from beta-A to sodalite, $G^{\prime}$ increases by $13 \%$. The structural class of sodalite is quantitatively distinguished from other classes with respect to all the indices.

Table 3 lists the accessibility of the solvent-accessible surface for different solvents, as well as fractal dimensions $D$ and $D^{\prime}$ for some zeolite fragments. The accessibility of the solvent-accessible surface is calculated for solvents with different molecular sizes. The radius of the solvent molecule varies from $R_{s}=1.250 \AA$ (representing a water molecule) to $R_{s}=3.500 \AA$ (protein side chain). On going from water to the side chain, the accessibility of the solvent-accessible surface monotonically decreases by $66 \%$ on average. In particular, for faujasite, the relative decrease in accessibility is the lowest and, for ZSM-5, the diminution in this property is the greatest. The fractal dimension $D$ of the solvent-accessible surface lies in the range 1.9-2.1, and its relative error is $1 \%$. On going from faujasite to sodalite (Table 1), $D$ increases by $14 \%$. In particular, for faujasite, ZSM-11, mordenite, and 
TABLE 3: Topological indices for zeolite fragments: accessibility and fractal dimension.

\begin{tabular}{|c|c|c|c|c|c|c|c|c|}
\hline Zeolite & Acc. $_{1}^{a}$ & Acc. 2 & Acc. 3 & $\mathrm{Acc}_{4}$ & Acc. 5 & Rel. decline Acc $_{5-1}(\%)$ & $D^{\mathrm{b}}$ & $D^{\prime c}$ \\
\hline Faujasite-I & 7.42 & 5.93 & 4.66 & 3.63 & 2.67 & 64.0 & 1.866 & 2.317 \\
\hline Faujasite-II & 9.64 & 7.74 & 6.07 & 4.58 & 3.37 & 65.0 & 1.912 & 2.193 \\
\hline ZSM-11 & 7.18 & 5.67 & 4.33 & 3.20 & 2.41 & 66.4 & 1.962 & 2.315 \\
\hline ZSM-5 & 7.75 & 6.07 & 4.56 & 3.26 & 2.46 & 68.3 & 2.026 & 2.174 \\
\hline Mordenite & 8.11 & 6.35 & 4.80 & 3.61 & 2.72 & 66.5 & 1.961 & 2.058 \\
\hline Beta-A & 7.64 & 6.16 & 4.83 & 3.55 & 2.48 & 67.5 & 1.981 & 2.215 \\
\hline
\end{tabular}

${ }^{a}$ Accessibility (\%) of the solvent-accessible surface for different solvents with radii $R_{s}$ : (1) water, $R_{s}=1.250 \AA$; (2) $R_{s}=1.617 \AA$; (3) $R_{s}=2.092 \AA$; (4) $R_{s}=2.706 \AA$; and (5) side chain, $R_{s}=3.500 \AA$.

${ }^{b}$ Fractal dimension of the solvent-accessible surface.

cFractal dimension of the solvent-accessible surface averaged for nonburied atoms.

beta-A, the $D$ are intermediate between that for a completely smooth line $(D=1)$ and that for a completely smooth surface $(D=2)$. However, for ZSM-5 and sodalite, the $D$ are intermediate between that for a completely smooth surface and that for a completely porous material $(D=3)$. $D$ increases, in general, with the relative decline of the accessibility (column 7 of Table 3). On the other hand, the atomic analysis of TOPO allows averaging $D$ only for nonburied atoms. The $D^{\prime}$ fractal dimension increases by $11 \%$ and lies in the range $2.1-$ 2.3. Thus, for all the zeolite fragments, the $D^{\prime}$ are intermediate between that for a completely smooth surface and that for a completely porous material. In particular, the pictures of faujasite, ZSM-11, mordenite, and beta-A change from a chanelled to a porous material. For mordenite, the $D^{\prime}-D$ increment is the smallest (5\%), and for ZSM-11, is the greatest (18\%). Thus, the structural class of mordenite is quantitatively distinguished from the other classes with respect to the $D^{\prime}-D$ increment.

Linear and quadratic correlation models of the fractal dimension $D$ have been carried out versus the structural properties of the zeolite crystals, as well as the geometric descriptors and topological indices of the fragments, via leastsquares regression. Faujasite-I is omitted in all the fits in order not to overweight this particular structure. The best linear regression for $D$ results are as follows:

$$
\begin{gathered}
D=1.69+0.0216 F_{d}+0.00958 R_{\max }-2.30 G+0.590 G^{\prime}, \\
\mathrm{PESS}=0.0248, \quad \mathrm{MAPE}=0.42 \%, \\
\mathrm{AEV}=0.0237, \quad r^{2}=0.9763,
\end{gathered}
$$

where the prediction error sum of squares (PESS), mean absolute percentage error (MAPE), approximation error variance (AEV), and coefficient of determination $\left(r^{2}\right)$ are reported. The zeolites (Table 1 ) are arbitrarily sorted. The linear model (cf. Figure 1(a)) incorrectly predicts the fractal dimensions of ZSM-11 and ZSM-5. Furthermore, the best quadratic model for $D$ results are as follows:

$$
\begin{gathered}
D=2.00-0.00337 z_{31}+0.0776 z_{32}+0.000519 z_{31} z_{32} \\
z_{31}=6.15-10.1 G-0.317 R_{\max } \\
z_{32}=0.898 z_{22}-0.135 z_{21}^{2}+0.158 z_{21} z_{22}+0.0341 z_{22}^{2}
\end{gathered}
$$

$$
\begin{gathered}
z_{21}=-8.81+0.541 F_{d}, \\
z_{22}=3.62 z_{11}+1.56 z_{12}+30.2 z_{11}^{2}-69.7 z_{11} z_{12}+37.5 z_{12}^{2}, \\
z_{11}=-11.2+1.48 F_{d}+81.7 G^{2}-4.21 G \cdot F_{d}, \\
z_{12}=6.15-10.1 G-0.317 R_{\max }, \\
\text { PESS }<0.00005, \quad \text { MAPE }=0.01 \% \\
\text { AEV }<0.00005, \quad r^{2}>0.99995
\end{gathered}
$$

and AEV decreases virtually by $100 \%$. The model results are superposed to the original data (Figure 1(b)), and the agreement is faultless.

A set of Brønsted-acid model units representative of $\mathrm{Si}-\mathrm{Al}$ zeolites is studied. The smallest unit investigated $\mathrm{SiH}_{3}-\mathrm{OH}-\mathrm{AlH}_{3}$ is taken to represent a bridged hydroxyl group; the remaining active-site models are built by closing rings consisting of $2-12-\mathrm{SiH}_{2}-\mathrm{OH}-\mathrm{AlH}_{2}-$ units (cf. Figure 2).

The internal cavities of these rings contribute to both total volume and fragment surface area. On the one hand, the total volume $V_{t}$ of the zeolite active-site models is the sum of both fragment $V_{f}$ and cavity $V_{c}$ volumes: $V_{t}=$ $V_{f}+V_{c}$. On the other, the fragment surface area $S_{f}$ is the sum of both external $S_{e}$ and cavity $S_{c}$ surface areas: $S_{f}=S_{e}+S_{c}$. Table 4 lists the geometric descriptors for the active-site models. The calculations labelled fragment + cavity have been carried out with SURMO2. SURMO2 is unable to recognize the internal cavities of the active-site models. Hence, the calculated volume $V$ is a measure of the total volume $V_{t}$; for example, for the 6-membered ring, $V_{t}$ equals $567.3 \AA^{3}$. Furthermore, GEPOL does recognize the cavities, and the value of the fragment volume $V_{f}$ is available; for example, $V_{f}\left(6\right.$-ring) $=490.9 \AA^{3}$. The external surface area $S_{e}(6$-ring $)=360.7 \AA^{2}$ is estimated by SURMO2. Besides, the actual (external plus internal) fragment surface area $S_{f}(6-$ ring) $=656.6 \AA^{2}$ (GEPOL).

Table 5 reports the topological indices for the zeolite active-site models. The fragment globularity $G$ is the topological index that better differentiates the active-site models. Not surprisingly, $G$ is rather greater as calculated by SURMO2 (closer to unity for the largest ring in the 


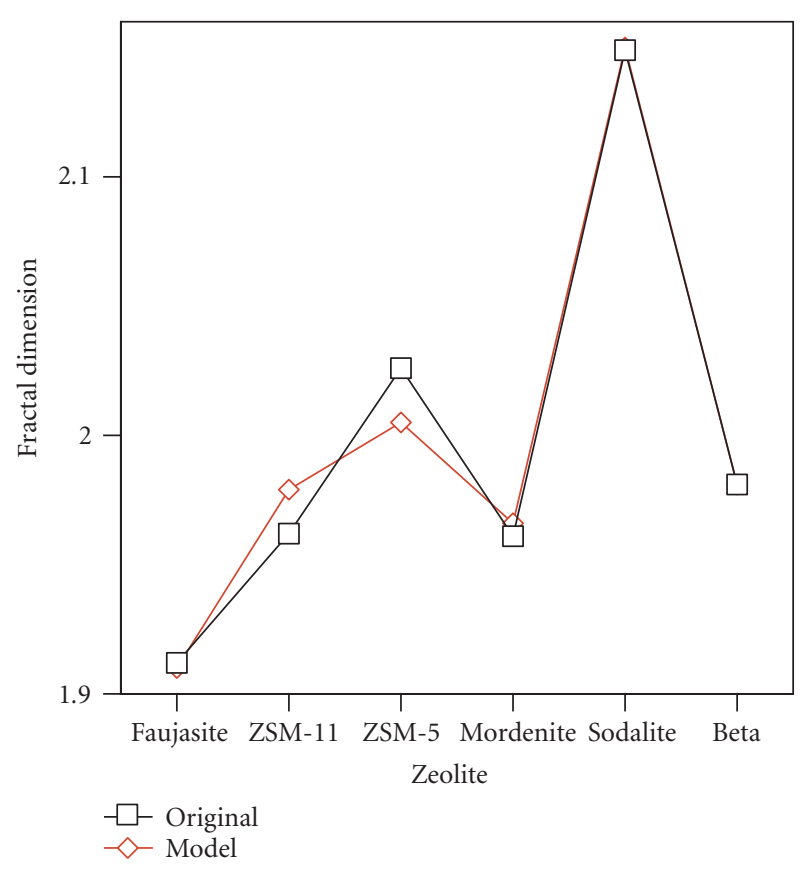

(a)

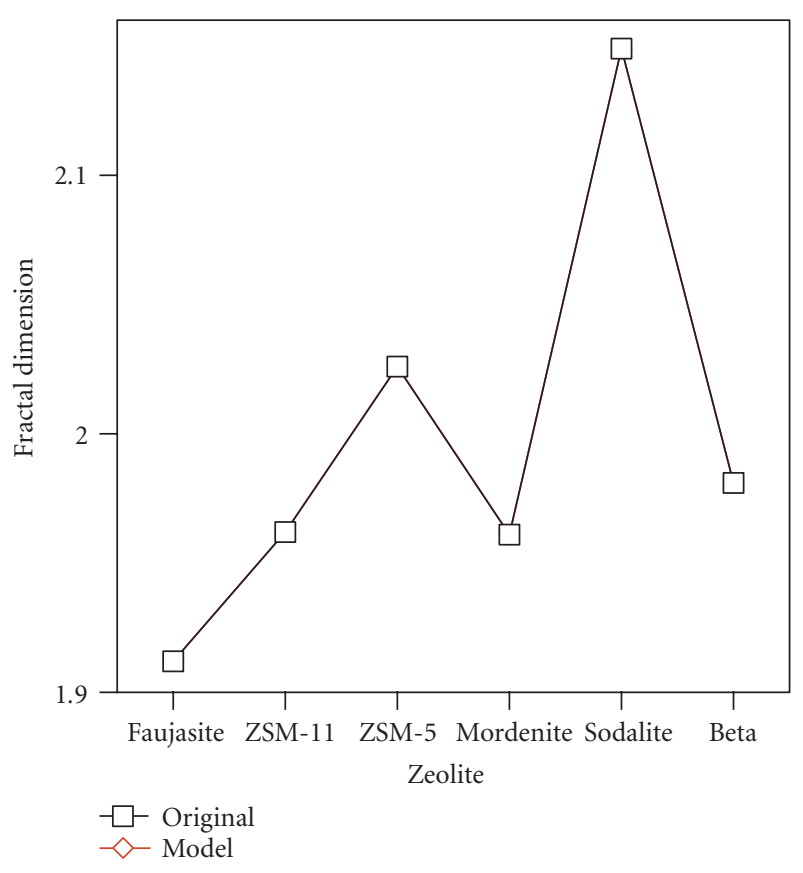

(b)

FIgURE 1: Comparison of data with models (fractal dimension): (a) linear and (b) quadratic models.

TABLE 4: Geometric descriptors for zeolite active-site models.

\begin{tabular}{|c|c|c|c|c|c|c|c|}
\hline Type of ring & $\begin{array}{c}V^{\text {a }} \text { fragment } \\
+ \text { cavity }\end{array}$ & $V^{\mathrm{b}}$ fragment & $\begin{array}{c}S^{c} \text { fragment } \\
+ \text { cavity }\end{array}$ & $S^{\mathrm{b}}$ fragment & $\begin{array}{c}\mathrm{AS}^{\mathrm{d}} \text { fragment } \\
+ \text { cavity }\end{array}$ & $A S^{b}$ fragment & $\mathrm{AS}^{\prime \mathrm{b}, \mathrm{e}}$ fragment \\
\hline 2 & 176.3 & 160.0 & 186.7 & 210.2 & 422.6 & 371.6 & 746.1 \\
\hline 4 & 433.5 & 328.8 & 346.0 & 439.6 & 652.4 & 659.7 & 1106.0 \\
\hline 6 & 567.3 & 490.9 & 360.7 & 656.6 & 854.9 & 992.2 & 1509.2 \\
\hline 8 & 813.4 & 660.9 & 414.6 & 907.9 & 959.4 & 1363.3 & 2052.6 \\
\hline 10 & 742.4 & 825.3 & 447.2 & 1135.5 & 910.9 & 1731.9 & 2631.2 \\
\hline 12 & 888.2 & 989.2 & 460.7 & 1360.7 & 1062.9 & 2091.8 & 3203.6 \\
\hline
\end{tabular}

aFragment volume $\left(\AA^{3}\right)$.

${ }^{\mathrm{b} C a l c u l a t i o n s ~ c a r r i e d ~ o u t ~ w i t h ~ t h e ~ G E P O L ~ p r o g r a m . ~}$

'Fragment surface area $\left(\AA^{2}\right)$.

dWater-accessible surface area $\left(\AA^{2}\right)$.

eSide-chain-accessible surface area $\left(\AA^{2}\right)$.

$G_{\text {fragment+cavity }}$ column) compared with GEPOL ( $\left.G_{\text {fragment }}\right)$. Moreover, the fragment rugosity $G^{\prime}$ is smaller. Note that the internal cavity effect is difficult to appreciate in the context of the fragment volume, globularity, and rugosity (10-12-ring), water-accessible surface (2-ring), and side-chain-accessible surface area (2-6-ring), because of their small or null calculated cavity contributions.

From the calculation results referring to the total (SURMO2) and cavity-sensitive (GEPOL) fragment shape, the geometric descriptors and topological indices for the cavities of the zeolite active-site models have been estimated. The results (cf. Table 6) show that the cavity volume and sur- face areas are smaller for the 6-ring than for the 8-ring. However, for the 6-ring, the globularity, rugosity, and fractal dimension are greater. Note that for the 2-8-ring cavities, $S>$ AS $\geq$ AS $^{\prime}$, because a water molecule with an effective radius of $1.41 \AA$ and a volume ca. $12 \AA^{3}$ can hardly be contained inside the smallest cavities. Moreover, a probe sphere representing a protein side chain, with a radius of $3.5 \AA$ and a volume ca. $180 \AA^{3}$, cannot be contained inside any of the cavities. For the 2-4- and 10-12-ring cavities, the fractal dimension $D$ is ca. 2, indicating that the solvent-accessible surface of these rings is hardly sensitive to solvent size. Notwithstanding, for the 6-8-ring cavities, $D$ lies in the range 4.0-4.3. 


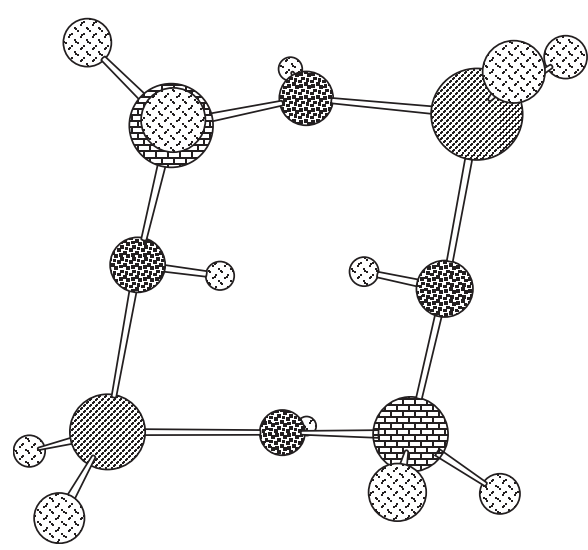

(a)

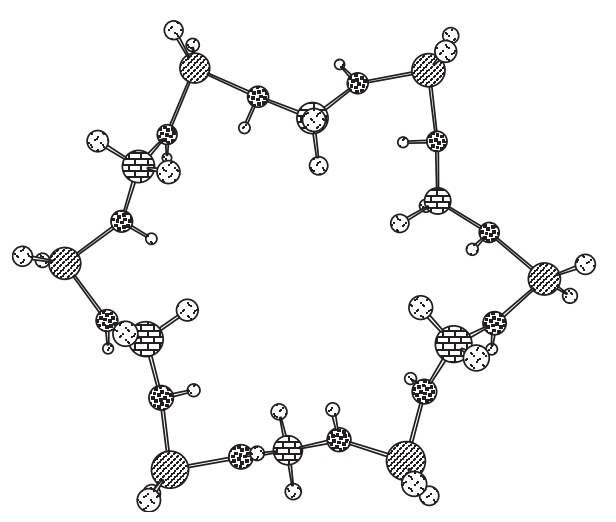

(c)

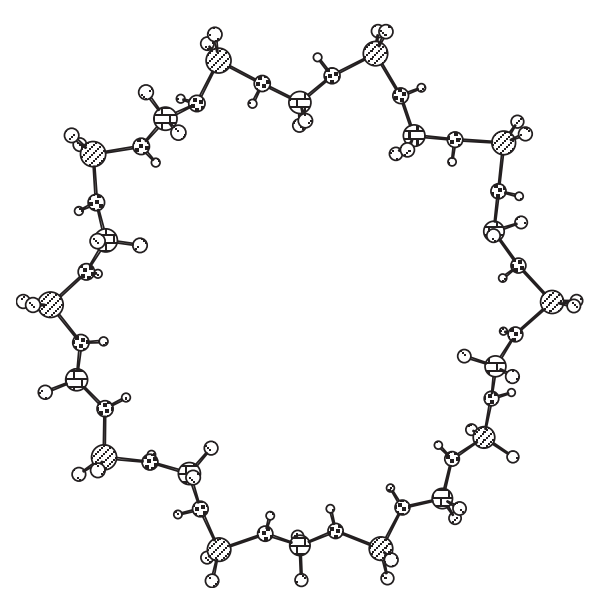

(e)

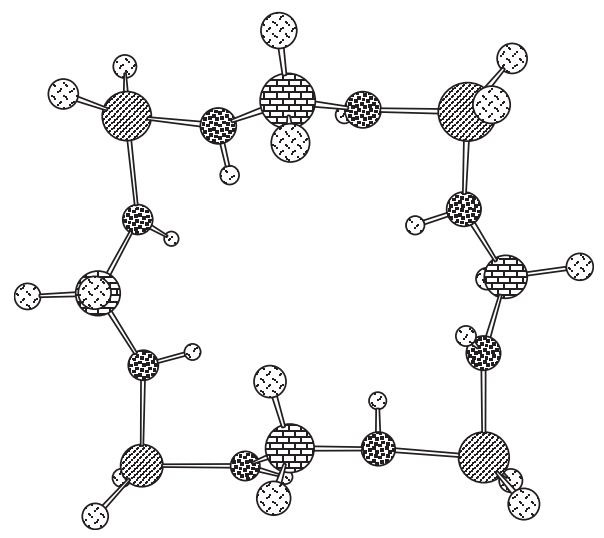

(b)

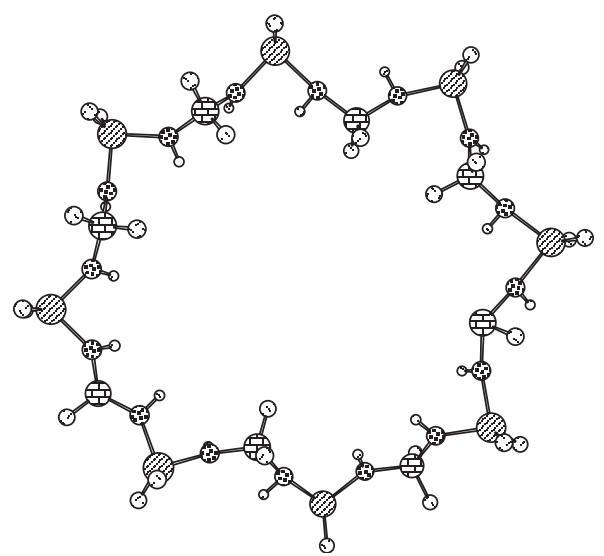

(d)

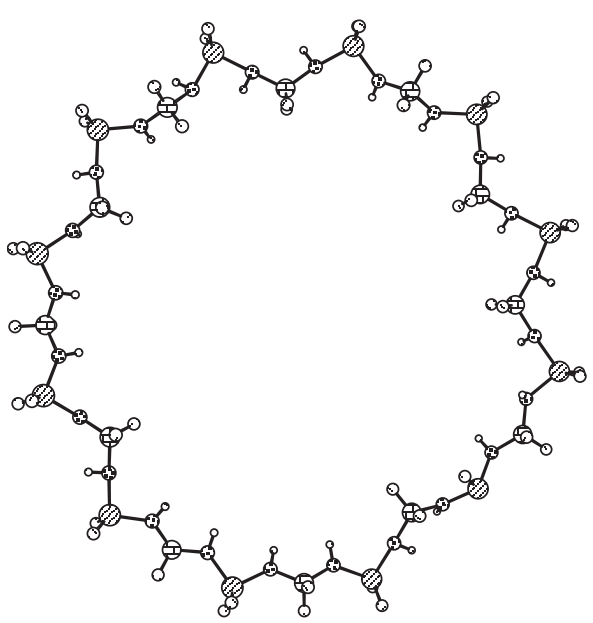

(f)

Figure 2: Molecular images of $-\left(\mathrm{SiH}_{2}-\mathrm{OH}-\mathrm{AlH}_{2}-\mathrm{OH}-\right)_{n}$ rings: (a)-(f) $n=2,4,6,8,10$, and 12 .

In particular, the 6-ring cavity shows the greatest value of $D$, indicating the greatest sensitivity of the cavity accessible surface to solvent size. Therefore, it is suggested that the 6-ring cavity can have the greatest Brønsted-acid catalytic activity.
Figure 3 shows the variation of the side-chain-accessible surface area $\left(\mathrm{AS}^{\prime}\right)$ with the water-accessible surface area (AS) of the zeolite active-site models for the 1-12-ring. Three points (1-, 2-, and 4-ring) appear superposed. 
TABLE 5: Topological indices for active-site models of zeolites.

\begin{tabular}{c|ccccc}
\hline Type of ring & $\begin{array}{c}G^{\mathrm{a}} \text { fragment } \\
+ \text { cavity }\end{array}$ & $G^{\mathrm{b}}$ fragment & $\begin{array}{c}G^{\mathrm{c}} \text { fragment } \\
+ \text { cavity }\end{array}$ & $G^{\text {b }}$ fragment & $\begin{array}{c}D^{\mathrm{d}} \text { fragment } \\
+ \text { cavity }\end{array}$ \\
\hline 2 & 0.814 & 0.678 & 1.059 & 1.313 & 1.262 \\
4 & 0.800 & 0.524 & 0.798 & 1.337 & 1.372 \\
6 & 0.919 & 0.458 & 0.636 & 1.337 & 1.372 \\
8 & 1.016 & 0.404 & 0.510 & 1.374 & 1.324 \\
10 & 0.887 & 0.375 & 0.602 & 1.376 & 1.501 \\
12 & 0.970 & 0.353 & 0.519 & 1.376 & 1.598 \\
\hline
\end{tabular}

aFragment globularity.

${ }^{\mathrm{b}}$ Calculations carried out with the GEPOL program.

'Fragment rugosity $\left(\AA^{-1}\right)$.

${ }^{\mathrm{d}}$ Fractal dimension of the solvent-accessible surface.

TABLE 6: Descriptors/indices for active-site model cavities.

\begin{tabular}{c|rrrrrrr}
\hline Type of ring & \multicolumn{1}{|c}{$V^{\mathrm{a}}$} & \multicolumn{1}{c}{$S^{\mathrm{b}}$} & \multicolumn{1}{c}{$\mathrm{AS}^{\mathrm{c}}$} & \multicolumn{1}{c}{$\mathrm{AS}^{\prime \mathrm{d}}$} & $G^{\mathrm{e}}$ & $G^{\mathrm{f}}$ \\
\hline 2 & 16.3 & 23.46 & 0.0 & 0.0 & 1.325 & 1.439 \\
4 & 104.7 & 93.56 & 7.3 & 0.0 & 1.148 & 0.894 \\
6 & 76.4 & 295.92 & 137.3 & 0.0 & 0.294 & 3.873 \\
8 & 152.5 & 493.34 & 403.9 & 45.3 & 0.280 & 3.235 \\
10 & 0.0 & 688.28 & 821.0 & 819.7 & 0.000 & $\infty .271$ \\
12 & 0.0 & 899.99 & 1028.9 & 1103.3 & 0.000 & $\infty$ & $\infty$ \\
\hline
\end{tabular}

aCavity volume $\left(\AA^{3}\right)$.

${ }^{b}$ Cavity surface area $\left(\AA^{2}\right)$.

cWater-accessible surface area $\left(\AA^{2}\right)$.

dSide-chain-accessible surface area $\left(\AA^{2}\right)$.

${ }^{\mathrm{e}}$ Cavity globularity.

${ }^{\mathrm{f}}$ Cavity rugosity $\left(\AA^{-1}\right)$.

gFractal dimension of the solvent-accessible surface.

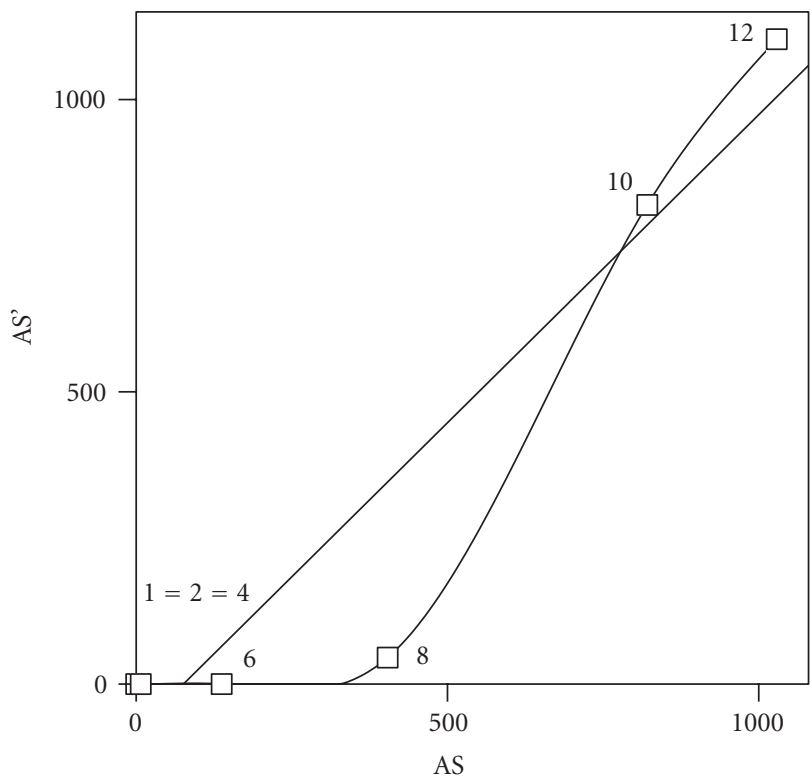

FIGURE 3: Side-chain versus water-accessible surface areas of active-site models of zeolites. 
TABLE 7: Geometric and topological indices for zeolite 6-ring active-site model: atomic analysis.

\begin{tabular}{|c|c|c|c|c|c|c|c|c|}
\hline Atom & $V^{\mathrm{a}}$ & $S^{\mathrm{b}}$ & $G^{\mathrm{c}}$ & $G^{\prime \mathrm{d}}$ & $\mathrm{AS}^{\mathrm{e}}$ & Accessibility $^{\mathrm{f}}$ & $\mathrm{AS}^{\prime \mathrm{g}}$ & $D^{\mathrm{h}}$ \\
\hline $\mathrm{Si}$ & 26.1 & 26.59 & 1.602 & 1.017 & 29.0 & 20.3 & 10.3 & 3.022 \\
\hline $\mathrm{O}$ & 6.5 & 6.49 & 2.591 & 1.001 & 3.2 & 3.6 & 0.1 & 5.749 \\
\hline $\mathrm{H}(\mathrm{O})$ & 7.7 & 9.09 & 2.076 & 1.179 & 3.2 & 3.5 & 8.9 & 2.963 \\
\hline $\mathrm{Al}$ & 9.8 & 11.41 & 1.941 & 1.164 & 2.9 & 3.2 & 0.1 & 5.594 \\
\hline Cavity & 76.4 & 295.92 & 0.294 & 3.873 & 137.3 & - & 0.0 & 4.271 \\
\hline All rings & 487.9 & 624.64 & 0.480 & 1.280 & 965.7 & 18.4 & 1490.6 & 1.584 \\
\hline
\end{tabular}

aRing volume $\left(\AA^{3}\right)$.

${ }^{\mathrm{b}}$ Ring surface area $\left(\AA^{2}\right)$.

'Ring globularity.

dRing rugosity $\left(\AA^{-1}\right)$.

eWater-accessible surface area $\left(\AA^{2}\right)$.

${ }^{\mathrm{f}}$ Accessibility (\%) of the water-accessible surface.

sSide-chain-accessible surface area $\left(\AA^{2}\right)$.

hFractal dimension of the solvent-accessible surface area.

The linear fit corresponds to

$$
\mathrm{AS}^{\prime}=-80.0+1.05 \mathrm{AS}, \quad r=0.953 \text {. }
$$

The slope indicates that an increase of $1.00 \AA^{2}$ in AS corresponds to an increase of $1.05 \AA^{2}$ in $\mathrm{AS}^{\prime}$. The abscissa (or the intersection with the interpolation line) at $\mathrm{AS}=76.2 \AA^{2}$ is closer to the 6-ring, indicating the greatest sensitivity of its solvent-accessible surface to solvent size.

The atom-to-atom analysis of the geometric descriptors and topological indices for the zeolite 6-ring activesite model, carried out with TOPO, considers (Table 7) four atoms, namely $\mathrm{Si}, \mathrm{O}, \mathrm{H}(\mathrm{O})$, and $\mathrm{Al}$ in each $-\mathrm{SiH}_{2}-$ $\mathrm{OH}-\mathrm{AlH}_{2}-$ unit. The greatest contribution to the ring volume $V$ comes from each $\mathrm{Si}$ atom $(52 \%$ of that for $\mathrm{Si} / \mathrm{O} / \mathrm{H} / \mathrm{Al})$. The same trend has been observed for the surface area $S_{\mathrm{Si}}(50 \%)$, as well as solvent-accessible surface areas $\mathrm{AS}_{\mathrm{Si}}(76 \%)$ and $\mathrm{AS}_{\mathrm{Si}}^{\prime}(53 \%)$, due to the greatest accessibility of each $\mathrm{Si}$ atom $\left(\mathrm{Acc}_{\mathrm{Si}}=20.3 \%\right)$. The Si-atom term in the ring globularity $G_{\mathrm{Si}}$ is the lowest. Moreover, each Siatom component part in the ring rugosity $G_{\mathrm{Si}}^{\prime}$ is small. Each Si-atom input to the ring fractal dimension $D_{\mathrm{Si}}$ is low; however, for the $\mathrm{O}$ atoms, $D_{\mathrm{O}}$ is the greatest, and for the $\mathrm{Al}$ atoms, $D_{\mathrm{Al}}$ is large. The ring cavity contributes to the total volume and surface area, as explained above (Table 5). Again, $S_{\text {cavity }}>\mathrm{AS}_{\text {cavity }} \geq \mathrm{AS}_{\text {cavity }}^{\prime}$, as expected for a small cavity. The fractal dimension $D_{\text {cavity }}$ is large, indicating the sensibility of the solvent-accessible surface of the cavity to solvent size and suggesting that this cavity can have large Brønsted-acid catalytic activity. The ring rugosity $G^{\prime}$ and accessibility are small. The ring fractal dimension $D$ is large.

Our results, indicating the maximal sensibility of the solvent-accessible surface of the 6-ring cavity to solvent size, are in agreement with Hammonds et al.'s rigid-unit crystal vibrational mode (RUM) model for the binding site of cations [26]. In faujasite, the 6-ring was calculated to be opening and closing under the influence of a local RUM, in agreement with experiments.

\section{CONCLUSIONS}

From the present results, the following conclusions can be drawn.

(1) The fragment globularity $G$ is the topological descriptor that better differentiates the zeolite active-site models.

(2) The 6-membered-ring cavity model of the zeolite active site shows the greatest fractal dimension, indicating the greatest sensitivity of its solvent-accessible surface to solvent size. Therefore, it is suggested that the 6-ring can have the greatest activity as acidic catalyst. Work is in progress to check the validity of this result.

\section{ACKNOWLEDGMENTS}

We wish to thank Dr. C. M. Zicovich-Wilson for providing us with calculation results before publication on the optimized geometry of zeolites. The authors acknowledge financial support from the Spanish MEC-DGI (Project no. CTQ200407768-C02-01/BQU), Generalitat Valenciana (DGEUI INF01-051 and INFRA03-047, and OCYT GRUPOS03-173), and Universitat de València-Mediscovery.

\section{REFERENCES}

[1] J. A. Rabo, Ed., Zeolite Chemistry and Catalysis, American Chemical Society, Washington, DC, USA, 1976.

[2] G. T. Kerr, "Hydrogen zeolite Y, ultrastable zeolite Y, and aluminum-deficient zeolites," Advances in Chemistry Series, vol. 121, pp. 219-229, 1973.

[3] R. M. Barrer, Hydrothermal Chemistry of Zeolites, Academic Press, New York, NY, USA, 1982.

[4] W. J. Mortier, J. Sauer, J. A. Lercher, and H. Noller, "Bridging and terminal hydroxyls. A structural chemical and quantum chemical discussion," Journal of Physical Chemistry, vol. 88, no. 5, pp. 905-912, 1984. 
[5] J. G. Fripiat, F. Berger-André, J.-M. André, and E. G. Derouane, "Non-empirical quantum mechanical calculations on pentasil-type zeolites," Zeolites, vol. 3, no. 4, pp. 306-310, 1983.

[6] P. J. O’Malley and J. Dwyer, "Ab initio molecular orbital calculations on the acidic properties of boralite," Journal of the Chemical Society, Chemical Communications, no. 2, pp. 72-73, 1987.

[7] P. J. O’Malley and J. Dwyer, "Ab initio molecular orbital calculations on the acidic characteristics of isomorphously substituted zeolites," Chemical Physics Letters, vol. 143, no. 1, pp. 97-100, 1988.

[8] H. W. Haynes Jr., "Chemical, physical, and catalytic properties of large pore acidic zeolites," Catalysis Reviews, vol. 17, pp. 273-336, 1978.

[9] P. A. Jacobs, "Acid zeolites: an attempt to develop unifying concepts (P. H. Emmett award address, 1981)," Catalysis Reviews, vol. 24, no. 3, pp. 415-440, 1982.

[10] P. Viruela-Martín, C. M. Zicovich-Wilson, and A. Corma, "Ab initio molecular orbital calculations of the protonation reaction of propylene and isobutene by acidic $\mathrm{OH}$ groups of isomorphously substituted zeolites," Journal of physical chemistry, vol. 97, no. 51, pp. 13713-13719, 1993.

[11] F. Torrens, "Fractal dimension of different structural-type zeolites and of the active sites," Topics in Catalysis, vol. 18, no. 3-4, pp. 291-297, 2002.

[12] F. Torrens, "Characterizing cavity-like spaces in active-site models of zeolites," Computational Materials Science, vol. 27, no. 1-2, pp. 96-101, 2003.

[13] F. Torrens, "Fractal dimension of zeolite catalysts," Molecular Physics, vol. 100, no. 19, pp. 3105-3109, 2002.

[14] F. Torrens, E. Ortí, and J. Sánchez-Marín, "Vectorized TOPO program for the theoretical simulation of molecular shape," Journal de Chimie Physique et de Physico-Chimie Biologique, vol. 88, pp. 2435-2441, 1991.

[15] A. Y. Meyer, "Molecular mechanics and molecular shape. Part 1. van der Waals descriptors of simple molecules," Journal of the Chemical Society, Perkin Transactions 2, pp. 1161-1169, 1985.

[16] A. Y. Meyer, "Molecular mechanics and molecular shape. V. On the computation of the bare surface area of molecules," Journal of Computational Chemistry, vol. 9, pp. 18-24, 1988.

[17] B. Lee and F. M. Richards, "The interpretation of protein structures: estimation of static accessibility," Journal of Molecular Biology, vol. 55, no. 3, pp. 379-400, 1971.

[18] R. B. Hermann, "Theory of hydrophobic bonding. II. Correlation of hydrocarbon solubility in water with solvent cavity surface area," Journal of Physical Chemistry, vol. 76, no. 19, pp. 2754-2759, 1972.

[19] A. Bondi, "Van der Waals volumes and radii," Journal of Physical Chemistry, vol. 68, no. 3, pp. 441-451, 1964.

[20] S. J. Wodak and J. Janin, "Analytical approximation to the accessible surface area of proteins," Proceedings of the National Academy of Sciences of the United States of America, vol. 77, no. 4, pp. 1736-1740, 1980.

[21] M. Lewis and D. C. Rees, "Fractal surfaces of proteins," Science, vol. 230, no. 4730, pp. 1163-1165, 1985.

[22] F. Torrens, J. Sánchez-Marín, and I. Nebot-Gil, "New dimension indices for the characterization of the solvent-accessible surface," Journal of Computational Chemistry, vol. 22, no. 5, pp. 477-487, 2001.
[23] F. Torrens, M. Rubio, and J. Sánchez-Marín, "AMYR 2: a new version of a computer program for pair potential calculation of molecular associations," Computer Physics Communications, vol. 115, no. 1, pp. 87-89, 1998.

[24] J. L. Pascual-Ahuir, E. Silla, J. Tomasi, and R. Bonaccorsi, "Electrostatic interaction of a solute with a continuum. Improved description of the cavity and of the surface cavity bound charge distribution," Journal of Computational Chemistry, vol. 8, no. 6, pp. 778-787, 1987.

[25] B. Terryn and J. Barriol, "On the evaluation of the usual quantities or coefficients related to the shape of a molecule approximated on the basis of the van der Waals radii," Journal de Chimie Physique et de Physico-Chimie Biologique, vol. 78, pp. 207-212, 1981.

[26] K. D. Hammonds, V. Heine, and M. T. Dove, "Rigid-unit modes and the quantitative determination of the flexibility possessed by zeolite frameworks," Journal of Physical Chemistry B, vol. 102, no. 10, pp. 1759-1767, 1998. 

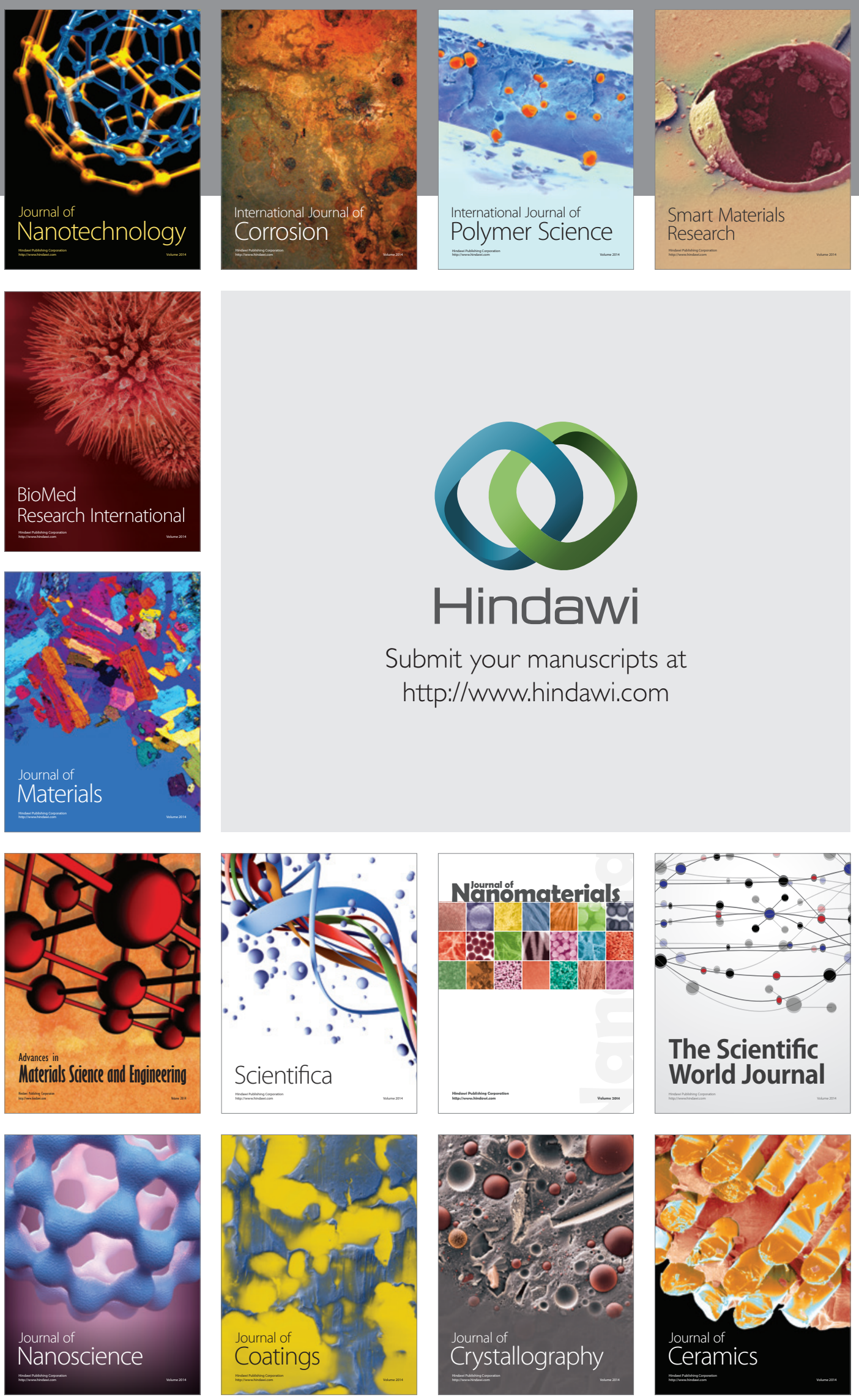

The Scientific World Journal

Submit your manuscripts at

http://www.hindawi.com

\section{World Journal}

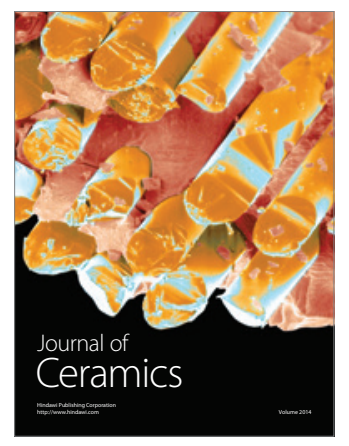

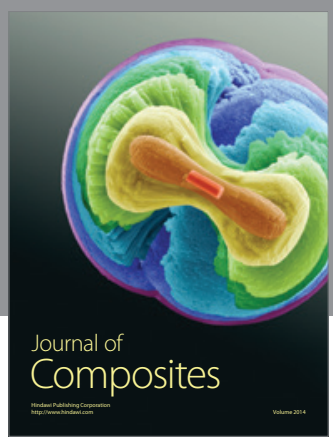
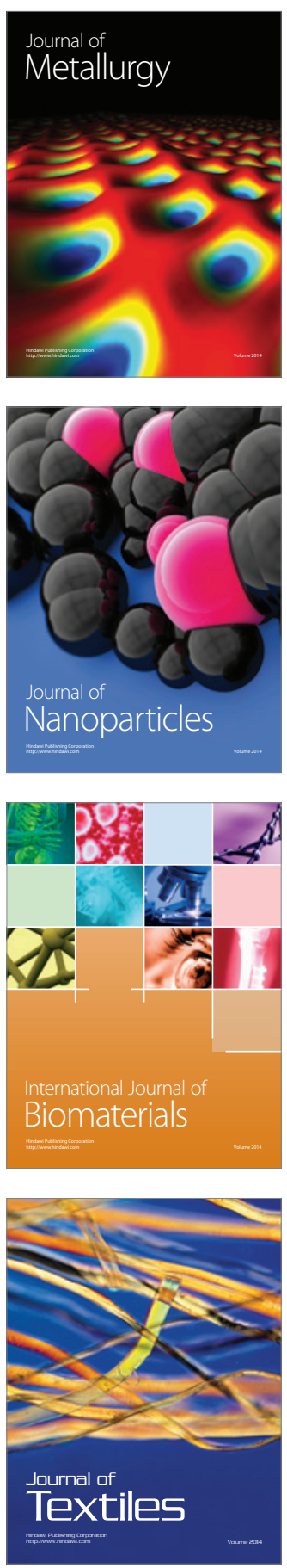